\title{
Frequency and findings of the acquired anorectal disease in the pediatric population with chronic constipation
}

\author{
Maria Teresa Sanchez-Avila¹, Oscar Alejandro Garcia-Valencia², Marian Rivas-Calderon ${ }^{2}$, \\ Luis Alonso Morales-Garza ${ }^{1}$, Perla Jacobo-Velazquez ${ }^{2}$, Karla Lorena Chavez-Caraza ${ }^{2}$ \\ ${ }^{1}$ Department of Internal Medicine, ${ }^{2}$ Department of Pediatrics, Escuela de Medicina y Ciencias de la Salud, Tecnologico de \\ Monterrey, Monterrey Nuevo Leon, Mexico.E-mail: karlachc@tec.mx \\ Received: 28th March 2017, Revised: 5th June 2017, 7th July 2017, 15th August 2017, \\ Accepted: 30th October 2017
}

SUMMARY: Sanchez-Avila MT, Garcia-Valencia OA, Rivas-Calderon M, MoralesGarza LA, Jacobo-Velazquez P, Chavez-Caraza KL. Frequency and findings of the acquired anorectal disease in the pediatric population with chronic constipation. Turk J Pediatr 2018; 60: 547-553.

To determine the frequency of anorectal disease associated with chronic constipation in children we conducted an observational, descriptive, retrospective study. One hundred and sixty eight patients were evaluated by anorectal manometry over a 10 -year period. The population was divided into organic constipation (OC) and functional constipation (FC) per ROME III criteria. Of those: $95(56.54 \%)$ presented with anorectal disease. The age range was 1-17 (mean 5.3). Eighteen presented with OC and 77 with FC. Acute anal fissure was found in 45 patients ( $38 \mathrm{FC}, 7 \mathrm{OC}$ ), chronic anal fissure in 38 ( $30 \mathrm{FC}, 8 \mathrm{OC}$ ), perianal erythema in 26 (23 FC, $3 \mathrm{OC})$, scar tissue was found in 28 ( $24 \mathrm{FC}, 4 \mathrm{OC}$ ), anal mucosa congestion in 27 (22 FC, 5 OC), hemorrhoidal disease in 26 ( $20 \mathrm{FC}, 6 \mathrm{OC})$ and perianal venous dilatation in 21 ( $16 \mathrm{FC}, 5 \mathrm{OC}$ ). Anal fissure, perianal erythema, and venous dilation occurred more frequently in patients with an anterior ectopic anus. An anal fissure was present in more than $80 \%$ of patients who had puborectalis muscle and external anal sphincter dysfunction.

We concluded that the frequency of acquired anorectal disease in children with chronic constipation is high; early diagnosis and treatment are priorities for the successful management of these patients.

Key words: constipation, children, anal fissure, functional constipation, hemorrhoids, rectal disease.

In the pediatric population, constipation has a prevalence up to $29 \%^{1}$ and approximately $3 \%$ of the general pediatric consultations and $25 \%^{2,3}$ of pediatric gastroenterology consultations are due to it. There is no statistical gender predominance. ${ }^{1,4}$ This condition has an important negative impact both on the quality of life of the children and the economic aspect amounting to health care related costs of around $\$ 6.9$ billion annually. 5

In the pediatric population, chronic constipation can be divided into 2 categories: functional and secondary to an organic cause. The functional type is by far the most prevalent $(90 \%)$ in the population outside the neonatal period and is usually multifactorial in origin. 2,6
The lack of appropriate diagnosis and treatment of chronic constipation can result in the development of gastrointestinal complications such as fecal incontinence, fecal impaction, abdominal pain, anal itching, rectal bleeding, anal or perianal fissures, sentinel skin tag, hemorrhoids, rectal prolapse, anorexia or nausea.

There are other non-GI complications such as enuresis or urinary tract infections. Affected patients often present with complaints like difficulty defecating, large, hard stools, pain and/or bleeding when defecating and edema in the anal region. ${ }^{7,8}$

On the approach of the children has with constipation it is important to identify the 
acquired anorectal diseases because if not treated early in the course can cause pain and discomfort to evacuate, perpetuating constipation and affecting significantly the quality of life of the pediatric patient.

The objective of this research is to determine the frequency of acquired anorectal disease associated with chronic constipation in children, to have evidence of the incidence of such diseases in the pediatric population.

\section{Material and Methods}

We reviewed the records of children referred to the Motility and Pelvic Floor Laboratory of the Hospital San Jose Tecnologico de Monterrey for chronic constipation over a period of 10 years (2004-2014).

Patients were sent for an anorectal manometry as they had been treated for functional constipation with conventional therapy based on osmotic laxatives and lifestyle changes without resolution or improvement of the problem for 1 month.

The population was divided into those with organic constipation, in which a cause or history of disease that accounted for the

Causes of constipation in our population $n=95$

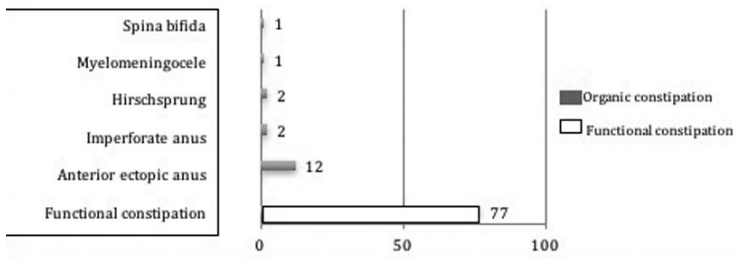

Fig. 1. Causes of constipation.

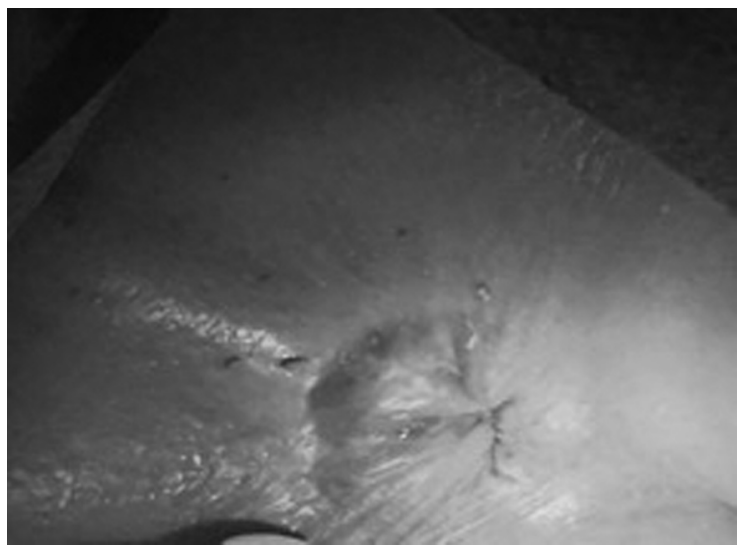

Fig. 2. Acute and chronic anal fissure: 10-year old-girl with constipation for 6 months associated with bleeding and rectal pain.

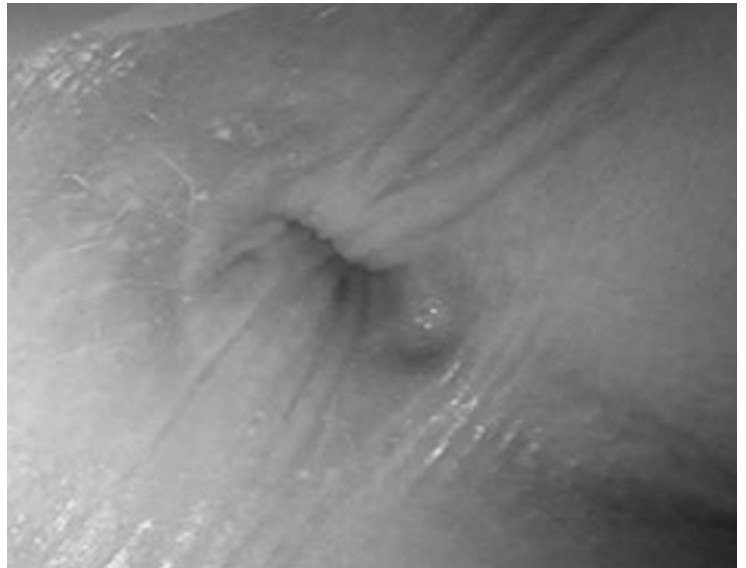

Fig 3. Acute anal fissure in a 4-year old boy with constipation for 5 months associated with pain.

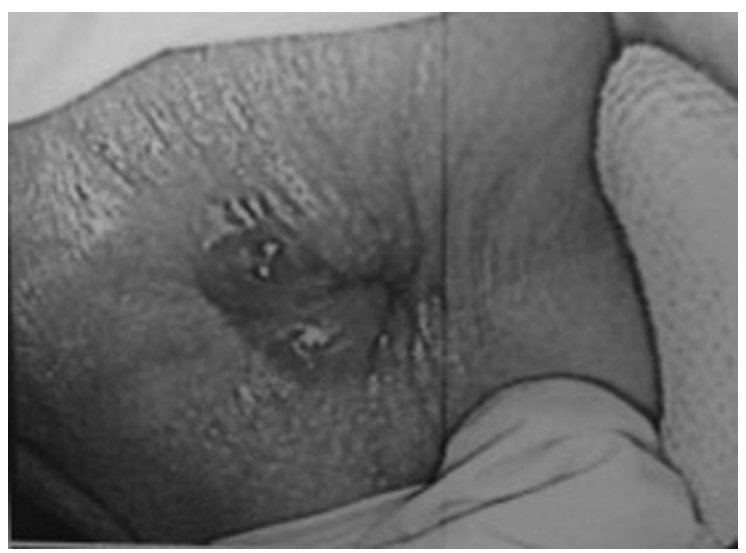

Fig. 4. Chronic anal fissure with external hemorrhoids.

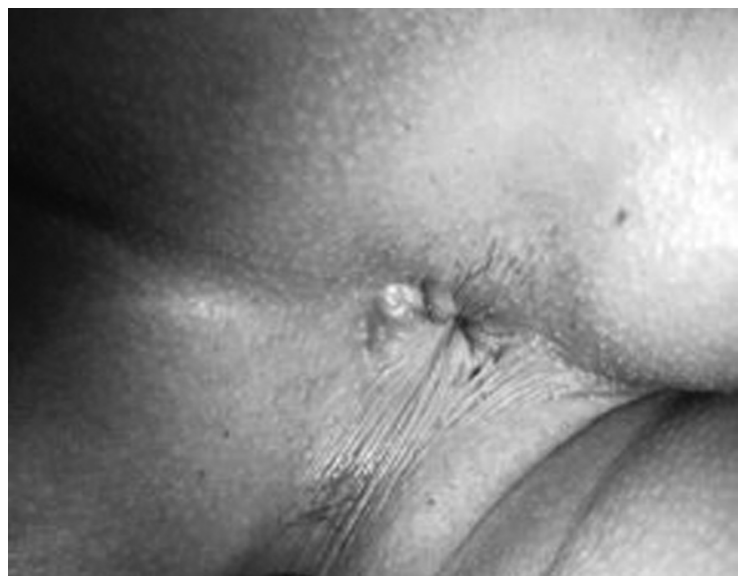

Fig 5. External hemorrhoids in a 17 -year-old male with constipation for 14 years associated with bleeding. 
constipation was found, and those with functional constipation, in which had no constipation-associated cause. We used the ROME III criteria classification system as it is the most accepted and widely recognized as the only standardized symptom-based criteria for the diagnosis of functional chronic constipation (Table I). $.9,10$

We searched retrospectively for sex, age, underlying disease, prior surgical procedures, history of biofeedback training, history of bleeding, difficulty or pain when defecating, large or hard stools and urinary disturbances.

As per protocol just prior to the manometric evaluation both groups underwent a physical examination directed towards finding manifestations of acquired anorectal pathology associated with chronic constipation. We searched for acute anal fissure, chronic anal fissure, scarring, hemorrhoidal disease, perianal erythema, anal mucosa congestion, perianal venous dilatation, perianal fistula or rectal prolapse.
The anorectal manometry was performed with a perfusion probe (Synectics ${ }^{\circledR}$ ) with 5 sensors that have a distance between them of $1 \mathrm{~cm}$ in radial order and a balloon in the distal portion. The Camodi technique was used for patient evaluation, who was placed in left lateral decubitus position with flexed legs, the lubricated probe was then inserted into the anal region until it reached a length of $10 \mathrm{~cm}$. The required values were obtained and the probe was removed with the "station pull-through" technique for the evaluation of the internal and external anal sphincter pressures. Those patients who did not cooperate received Chloral hydrate $(70 \mathrm{mg} / \mathrm{kg} \mathrm{PO})$ as sedative. The parameters used were Internal Anal Sphincter (IAS) resting pressure, External Anal Sphincter (EAS) resting pressure, IAS squeeze pressure, EAS squeeze pressure, anal canal length, rectal ampulla pressure, Presence of Rectal Anal Inhibitory Reflex, Volume of conscious perception, volume of defecation desire, maximum tolerable volume and abdominopelvic coordination.

Table I. Diagnostic Criteria for Functional Constipation. ${ }^{25}$

Diagnostic Criteria For Functional Constipation In children $>4$ Years Of Age

Must include at least two of the following in a child with insufficient criteria for diagnosis of IBS

Two or fewer defecations in the toilet per week

At least one episode of fecal incontinence per week

History of retentive posturing or excessive volitional stool retention

History of painful or hard bowel movements

Presence of a large fecal mass in the rectum

History of large diameter stools which may obstruct the toilet

Criteria fulfilled at least once per week for at least two months prior to diagnosis.

Diagnostic Criteria For Functional Constipation In Children $<4$ Years Of Age

Must include at least two of the following for at least a month

Two or fewer defecations per week

At least one episode/week of incontinence after the acquisition of toileting skills

History of excessive stool retention

History of painful or hard bowel movements

Presence of a large fecal mass in the rectum

History of large diameter stools which may obstruct the toilet

Accompanying symptoms may include irritability, decreased appetite and/or satiety. The accompanying symptoms disappear immediately following passage of large stool. 
Table II. Associated Complications.

\begin{tabular}{|c|c|c|c|c|c|c|}
\hline & $\begin{array}{c}\text { Functional } \\
\text { constipation } \\
\quad(77)\end{array}$ & $\begin{array}{l}\text { Anterior } \\
\text { ectopic } \\
\text { anus (12) }\end{array}$ & $\begin{array}{l}\text { Imperforate } \\
\text { anus (2) }\end{array}$ & $\begin{array}{c}\text { Myelomeningocele } \\
\text { (1) }\end{array}$ & $\begin{array}{c}\text { Spina } \\
\text { bifida } \\
\text { (1) }\end{array}$ & $\begin{array}{l}\text { Hirschsprung } \\
\text { (2) }\end{array}$ \\
\hline Acute anal fissure & 38 & 4 & & 1 & 1 & 1 \\
\hline $\begin{array}{l}\text { Chronic anal } \\
\text { fissure }\end{array}$ & 30 & 6 & 1 & 1 & & \\
\hline Scar tissue & 24 & 4 & & & & \\
\hline Perianal erythema & 23 & 1 & & & 1 & 1 \\
\hline $\begin{array}{l}\text { Anal mucosa } \\
\text { Congestion }\end{array}$ & 22 & 5 & & & & \\
\hline $\begin{array}{l}\text { Hemorrhoidal } \\
\text { Disease }\end{array}$ & 20 & 3 & 1 & 1 & & 1 \\
\hline $\begin{array}{l}\text { Perianal venous } \\
\text { dilation }\end{array}$ & 16 & 5 & & & & \\
\hline Rectal prolapse & 5 & & & 1 & & \\
\hline Perianal erosion & 3 & & 1 & & & \\
\hline Anal fistula & 1 & & & & & 1 \\
\hline Fibrosis & 1 & & 2 & & & \\
\hline
\end{tabular}

This study was approved by the Ethical Committee (13CEI19039139) and the National Bioethics Commission (CONBIOETICA19CEI00820130520).

\section{Statistical analysis}

Results are described as means and standard deviation for continuous variables and as frequencies and proportions for the discrete variables. MS Excel 2013 and SPSS20 were used for the statistical analysis. We calculated the odds ratio for the risk factors in the development of anorectal pathology.

\section{Results}

A total of 168 patient records were examined. Of those 95 presented with anorectal pathology, 43 being girls ( $45.26 \%$ ) and 52 boys (54.72\%). The age range of the studied population was 1-17 years old with a mean of 5.3 years.

Of those who had anorectal disease 18 presented with constipation secondary to an organic cause (18.94\%) finding a history of ectopic anus in $12(66.66 \%)$, Hirschsprung 's disease in $2(11.11 \%)$, history of imperforate anus in 2 $(11.11 \%), 1$ patient with myelomeningocele $(5.55 \%)$ and 1 with spina bifida $(5.55 \%)$ (Fig. 1). On the other hand, 77 patients had functional constipation (81.05\%). Regarding anorectal disease 62 patients $(65.26 \%)$ presented with 2 or more coexisting lesions. Acute anal fissure was found in 45 patients (38 FC, 7 OC), chronic anal fissure in 38 (30 FC, 8 OC), perianal erythema in 26 (23 FC, 3 OC), scar tissue in 28 (24 FC, 4 OC), mucous anal congestion in 27 (22 FC, 5 OC), hemorrhoidal disease in 26 (20 FC, 6 OC) and perianal venous dilatation in 21 (16 FC, 5 $\mathrm{OC})$. Other injuries found were rectal prolapse in 6 ( $5 \mathrm{FC} 1 \mathrm{OC})$, perianal erosion in $4(3$ FC 1 OC) perianal fibrosis in 3 (1 FC, 2 OC) and anal fistula in 2 (1 FC 1 OC). (Table II).

Patients with anterior ectopic anus presented more frequently with anal fissure (83.33\%), perianal erythema $(41.66 \%)$ and perianal venous dilation (33.33\%).

Relevant manometric findings associated with acquired anorectal pathology were found in 43 patients: 26 presented with puborectalis muscle dysfunction, 8 with external sphincter dysfunction and 9 with combined dysfunction. The most common anorectal finding in these patients was anal fissure presenting in $84.6 \%$ of the patients with puborectalis muscle dysfunction, $87.5 \%$ on those with external sphincter dysfunction and all of those with combined dysfunction. 
Table III. Risk factors for the development of Anorectal Pathology

\begin{tabular}{lcccc}
\hline & Variable & Odds ratio & $\begin{array}{c}\text { Confidence } \\
\text { interval }\end{array}$ & P value \\
\hline Constipation & Functional & Referent & & \\
& Organic & 1.01 & $(0.37-2.74)$ & 0.98 \\
Sex & Female & Referent & & \\
& Male & 0.76 & $(0.40-1.46)$ & 0.42 \\
Age (yr) & $\geq 9$ & Referent & & \\
& $<9$ & 2.14 & $(1.11-4.13)$ & 0.02 \\
Treatment with & & & & \\
biofeedback & No & Referent & & 0.08 \\
& Yes & 3.05 & $(0.87-10.64)$ & \\
\hline
\end{tabular}

We tested the importance of the population characteristics such as type of constipation (functional vs organic) sex, age and history of biofeedback treatment as risk factors for the development of anorectal pathology. Only age accounting for significant statistical difference ( $\mathrm{p}$ value 0.02 ). (Table III).

\section{Discussion}

The acquired anorectal disease has been extensively studied in adults, so its diagnosis and treatment are well established in this population. However, this is not true in the pediatric population as this disease is poorly described and thought to be uncommon in this age group. This lack of information often leads pediatricians to overlook its manifestations and therefore not detect them and treat them in properly fashion.

Regarding the findings in this study, there was no difference between the proportion of males and females evaluated, which is consistent with the results of Van den Berg's systematic review ${ }^{1}$ and described by Medeiros et al. ${ }^{4}$ and Rajindrajith et al. ${ }^{11}$ who found no significant association between gender and constipation.

Anal fissures are defined as the laceration of the anal mucocutaneous junction. It is an acquired lesion of unknown etiology likely secondary to the forceful passage of a hard stool related with constipation. ${ }^{12}$ They can be classified into acute ( $<6$ weeks) or chronic ( 6 weeks or more). The former usually appear as a simple laceration (linear appearance) in the anus (Fig. 2 and 3) while the latter have a triangular appearance and can be accompanied by edema and fibrotic tissue (Fig. 4) tend to be more difficult to treat and can be associated with an external elevation and/or extra tissue within the anal canal referred as hypertrophic papillae. They mostly occur along the posterior midline and the presence outside this position should lead to thinking of other conditions or comorbidities. In some cases, as previously described, they can be the cause and not the consequence of constipation. The percentage of patients with a fissure in our study was much higher $(88 \%)$ than reported in previous studies such as Dehghani et al. ${ }^{9}$ (7.2\%) and Aydogdu et al. ${ }^{13}$ (26.9\%). Likewise, perianal erythema was more prevalent $(29.8 \%)$ when compared to Dehghani et al. ${ }^{9}(13.1 \%)$.

History of surgically corrected imperforate anus (usually by posterior sagittal ano rectoplasty) has been associated with a slightly higher percentage of long-term constipation (30.7\%) 14 being the most common disorder found in these patients. ${ }^{15}$ In our study $50 \%$ of patients with a history of imperforate anus presented with chronic anal fissure, however being a small sample $(n=2)$ we recommend further investigation.

Anterior ectopic anus refers to an anorectal malformation observed only in women and characterized by an essentially normal appearing anus in an abnormally anterior position of 
the midpoint between the fourchette and the coccyx. ${ }^{16}$ The anal canal is primarily located within the voluntary sphincter complex differentiating it from the perineal fistula. Kyrklund et al. ${ }^{17}$ found a prevalence of constipation of $36 \%$ in patients with this disease as compared with the $13 \%$ found of their control cases. In our study, the high prevalence of anal fissure (83.33\%), perianal erythema $(41.66 \%)$ and perianal venous dilatation $(33.33 \%)$ in these cases suggests a possible association between the two conditions.

In patients with pelvic floor dysfunction, the ability to relax the muscles during defecation is altered resulting in a paradoxical (inappropriate) contraction. This has been recognized as a major cause of chronic functional constipation presenting in up to $50 \%$ of these patients. ${ }^{18}$ The etiology of this pattern is not entirely clear yet it has been associated with a brainintestinal axis dysfunction and/or acquired behavioral failure secondary to pain, stress or trauma. ${ }^{19}$ The latter being the basis for anorectal biofeedback and psychotherapy as treatment, both demonstrating positive changes in rates of motility and symptomatology. ${ }^{20}$ The excessive tension exerted against an unrelaxed, closed anal canal can contribute to the development of other anorectal pathology with complications such as anal fissures, hemorrhoids, rectocele, solitary rectal ulcer or coccidynia. ${ }^{19}$ This is consistent with our manometry findings suggestive of a relationship between the puborectalis muscle and external anal sphincter dysfunction with the presence of anal fissures being higher when combined dysfunction is present than either one alone.

Hemorrhoids are extremely rare in children with an increasing prevalence in adolescents and adults, ${ }^{21}$ however there is insufficient data regarding the incidence in the pediatric population. ${ }^{22}$ They are more common in children with portal hypertension with an estimate between 4 y $32 \%{ }^{23}$ yet these are rarely symptomatic. ${ }^{24,25}$ When present symptoms may include hemorrhage, prolapse, itching and pain; (Fig. 5) the stools may be bloody or parents may observe a bulge or dilated venous plexus at the anal orifice. The latter being more typical in children with chronic constipation. ${ }^{21}$ In our study the prevalence of children with hemorrhoids was common (27\%), being higher in the patients with organic vs. functional constipation (33.33\% vs. $25.97 \%$ ). Even as this is not regarded as a problem of childhood, in our study we found a mean age of 8 years old for the patients with this presentation, this would suggest a strong correlation between chronic constipation and early onset of hemorrhoidal disease.

We acknowledge in the limitations of our study that the higher prevalence of anorectal disease found in our patients when compared with most studies could be explained because our study was conducted in patients with a long-standing pathology and who had already been treated by another specialist without improvement in the symptoms and therefore were referred for a more thorough evaluation, representing this as a selection bias.

In the present study, a high prevalence of acquired anorectal disease in the children with chronic functional constipation was found unlike previously reported in the literature. Thus, we recommend an adequate management and follow up in the assessment of the children with a history of constipation in order to avoid the development of acquired anorectal lesions as they could contribute to pain and discomfort to evacuate perpetuating the behavioral painretention cycle and its very important negative impact on the quality of life of the pediatric patients and the family economics.

When assessing children with constipation and a history of pain or bleeding a thorough examination of the perianal region is warranted to identify acquired anorectal lesions such as hemorrhoids and anal fissures that can be perpetuating the symptomatology. Among the causes of constipation anterior ectopic anus should be considered, as it is strongly associated with the anorectal pathology. The frequency of acquired anorectal disease in our studied population is high; early diagnosis and treatment are priorities for the successful management of these patients.

All procedures performed in studies involving human participants were in accordance with the ethical standards of the institutional and/or national research committee and with the 1964 Helsinki declaration and its later amendments or comparable ethical standards. 
For this type of study formal consent is not required.

\section{Acknowledgements}

We would like to thank Dr. Gonzalez-Camid, Estrella, Dr. Uscanga-Vicarte, Victor, Dr. Urquidi-Rivera, Martha and Dr. Cura-Esquivel, Idalia for helping us review each of their cases.

\section{REFERENCES}

1. van den Berg MM, Benninga MA, Di Lorenzo C. Epidemiology of childhood constipation: a systematic review. Am J Gastroenterol 2006; 101: 2401-2409.

2. Evaluation and treatment of constipation in children: summary of updated recommendations of the North American Society for Pediatric Gastroenterology, Hepatology and Nutrition. J Pediatr Gastroenterol Nutr 2006; 43: 405-407.

3. Walia R, Mulheran N, Khan R, Cuffari C. Chronic Constipation in Children: An Overview. Practical Gastroenterology 2013;XXXVII: 19. Available at https:// med.virginia.edu/ginutrition/wp-content/uploads/ sites/199/2014/06/Parrish_July_2013.pdf Accessed March 15, 2016

4. Medeiros LC da S, Morais MB de, Tahan S, Fukushima E, Motta MEFA, Fagundes-Neto U. Clinical characteristics of pediatric patients with chronic constipation according to age group. Arq Gastroenterol 2007; 44: 340-344.

5. Wald A, Sigurdsson L. Quality of life in children and adults with constipation. Best Pract Res Clin Gastroenterol 2011;25: 19-27.

6. Gibas-Dorna M, Piatek J. Functional constipation in children - evaluation and management. Prz Gastroenterol 2014; 9: 194-199.

7. Dehghani SM, Kulouee N, Honar N, Imanieh M-H, Haghighat M, Javaherizadeh H. Clinical manifestations among children with chronic functional constipation. Middle East J Dig Dis 2015; 7: 31-35.

8. Motta ME, Silva GA. Signs and symptoms associated with chronic constipation. J Pediatr (Rio J) 2000; 76: 222-226.

9. Longstreth GF, Thompson WG, Chey WD, Houghton LA, Mearin F, Spiller RC. Functional bowel disorders. Gastroenterology 2006; 130: 1480-1491.

10. Tack J, Muller-Lissner S, Stanghellini V, et al. Diagnosis and treatment of chronic constipation--a European perspective. Neurogastroenterol Motil 2011; 23: 697710.

11. Rajindrajith S, Devanarayana NM, Adhikari C, Pannala W, Benninga MA. Constipation in children: an epidemiological study in Sri Lanka using Rome III criteria. Arch Dis Child 2012;97: 43-45.
12. Akay B, Klein MD. Surgical conditions of the anus and rectum. In: Kliegman RM, Stanton BF, St Geme JW III, Schor NF, Behrman RE (eds). Nelson Textbook of Pediatrics (20th ed). Philadelphia, PA: Elsevier, 2016: 1894-1900.

13. Aydogdu S, Cakir M, Yuksekkaya HA, Arikan C, Tümgör G, Baran M, Yağci RV. Chronic constipation in Turkish children: Clinical findings and applicability of classification criteria. Turk J Pediatr 2009; 51: 146153.

14. Nam SH, Kim DY, Kim SC. Can we expect a favorable outcome after surgical treatment for an anorectal malformation? J Pediatr Surg 2016; 51: 421-424.

15. Rintala R, Lindahl H, Marttinen E, Sariola $H$. Constipation is a major functional complication after internal sphincter-saving posterior sagittal anorectoplasty for high and intermediate anorectal malformations. J Pediatr Surg 1993; 28: 1054-1058.

16. Arango, M.E. Constipacion, Incontinencia y otros problemas anorrectales. In: Uribe FL, Arango ME (eds.) Cirugia Pediatrica Colombia: Editorial Universidad de Antioquia; 2006: 437-444.

17. Kyrklund K, Pakarinen MP, Taskinen S, Rintala RJ. Bowel function and lower urinary tract symptoms in females with anterior anus treated conservatively: Controlled outcomes into adulthood. J Pediatr Surg 2015; 50: 1168-1173.

18. Nikjooy A, Maroufi N, Ebrahimi Takamjani I et al. MR defecography: a diagnostic test for the evaluation of pelvic floor motion in patients with dyssynergic defecation after biofeedback therapy. Med J Islam Repub Iran 2015; 29: 188

19. Tries, J. Disorders Related to Excessive Pelvic Floor Muscle Tension. International Foundation for Functional Gastrointestinal Disorders 2012. Available at www. iffgd.org. Accessed March 15, 2016

20. Bassotti G, Chistolini F, Sietchiping-Nzepa F, de Roberto G, Morelli A, Chiarioni G. Biofeedback for pelvic floor dysfunction in constipation. BMJ 2004; 328: 393-396.

21. Stites T, Lund DP. Common anorectal problems. Semin Pediatr Surg 2007;16: 71-78.

22. Grossmann O, Soccorso G, Murthi G. LigaSure Hemorrhoidectomy for Symptomatic Hemorrhoids: First Pediatric Experience. Eur J Pediatr Surg 2015; 25: 377-380.

23. Heaton ND, Davenport M, Howard ER. Incidence of haemorrhoids and anorectal varices in children with portal hypertension. Br J Surg 1993; 80: 616-618.

24. Heaton ND, Davenport M, Howard ER. Symptomatic hemorrhoids and anorectal varices in children with portal hypertension. J Pediatr Surg 1992;27: 833-835.

25. Drossman DA, Corazziari E, Delvaux M, Spiller RC, Talley NJ, Thompson WG, Whitehead WE (Editors). Rome III: The Functional Gastrointestinal Disorders, Third Edition. McLean, VA: Degnon Associates, Inc., 2006. 